\title{
LA NOVELA CORTA Y LAS FORMAS DE LA MEMORIA: DIARIO DEL DOLOR DE MARÍA LUISA PUGA
}

\author{
Elsa Leticia García Argüelles \\ Universidad Autónoma de Zacatecas \\ elsalet_35@hotmail.com
}

Resumen: En este ensayo analizo la novela corta Diario del dolor (2004), de María Luisa Puga, autora mexicana de los años setenta que remite al lector a su propia vida tejida con la ficción. El eje del ensayo revisa la estructura del diario y el uso de lo autobiográfico en las formas que adquiere la memoria, materia privilegiada del pensamiento estético en toda su obra. Diario del dolor se escribe en agonía, y es un homenaje a la consciencia del acto de escribir, del cuerpo y la figura de la escritora. El personaje Dolor es humanizado a través de la voz que narra y su memoria, y, de este modo, se transmuta el cuerpo físico enfermo/discapacitado en un cuerpo textual en armonía, evocando reflexiones entre la sombra y la luz. Así mismo, se revisa la construcción de la novela corta y del proyecto editorial, el cual se estructura en pequeños relatos cortos que dan unidad a la narración en su conjunto a través de fragmentaciones y fractales, recreando imágenes entre el orden y el caos. Se siguen los recuerdos en la enunciación y la reescritura de la memoria a partir de los "cuadernos" que acompañaron su vida literaria como autora/lectora/persona para integrar la metaficción, la intertextualidad y la ironía.

Palabras clave: memoria, narración, fragmentación, fractales, lector.

\section{THE SHORT NOVEL AND THE SHAPES OF THE MEMORY: DIARIO DEL DOLOR BY MARÍA LUISA PUGA}

\begin{abstract}
In this essay, I analyze the short novel called Diario del dolor [Pain Diary] (2004), by María Luisa Puga, Mexican author from the seventies who refers the reader to her own life interwoven with fiction. The essay axis revises the structure of the diary and the use of the autobiographic, in the forms which memory adheres privileged matter from the aesthetic thought in all of his work. Diario del dolor is written in agony and it is a tribute to the consciousness of the act of writing, the body, and the writer's figure. The character Pain is humanized through the voice which narrates and her memory. Therefore, the physically ill/disabled body transmutes into the textual body in harmony, evoking reflections between dark and light. Moreover, the construction of the short novel and the editorial project, which is structured in small short stories, unites the narration through fragmentations and fractals, recreating images between order and chaos. Memories are followed in the enunciation, and the memory rewriting is based on the "notebooks" that accompanied her literary life as an author/reader/person to integrate metafiction, intertextuality and irony.
\end{abstract}

Keywords: memory, narration, fragmentation, fractals, reader. 
DOI: https://doi.org/10.24029/lejana.2020.13.441

Recibido: el 2 de noviembre de 2018

Aceptado: el 1 de marzo de 2019

Publicado: el 19 de febrero de 2020 
Hoy no me duele nada aunque todo esté presente: la cadera, las rodillas, el hombro, el sueño, el reposet ${ }^{1}$ que no se deja amansar.

Antes sí porque yo tenía fuerzas. Ahora, porque no tengo, ya no.

No se tiene memoria del dolor hasta el momento en que llegas

para quedarse. Es cuando nos tenemos que adaptar, o aprender a ser alguien distinto de lo que éramos y a usarnos de otra manera.

Qué raro ha sido y qué nuevo. Por eso te he escrito tanto.

MARÍA LUISA PUGA

En lo que a mí respecta, continuaré mi caminar hacia el silencio en busca de una obra breve que, sin embargo, posea la gravedad de la nada, el peso de una sombra: un algo que se aproxime a la sabiduría que trae consigo la muerte.

GUILLERMO FADANELLI

\section{La novela corta: La fragmentación y los fractales}

La crítica y la historiografía literaria han ido anexando a la definición de novela corta características, intenciones y formas que legitiman esquemas de lectura, textualidad donde los géneros "mayores y menores" se escapan y se renuevan constantemente. Los géneros se miden en párrafos y en palabras, están más lejos o más cerca de un canon, más lejos o más cerca de la intuición; lo imprescindible es desplazarse en territorios que provoquen los sentidos del lector, en primer o segundo grado, como afirma Roland Barthes, respecto a la labor del crítico literario. ${ }^{2}$ Los géneros literarios relacionados con el relato breve y la novela breve se encuentran en una zona fronteriza, plena de préstamos y cruces, alimentándose mutuamente:

El estudio de los cuentos integrados, es decir, de la serie de cuentos con unidad temática, genérica o estilística, se inscribe en la discusión sobre la escritura fronteriza, ya que estas series de textos breves se encuentran a medio camino entre la novela y el cuento (en términos de extensión y estructura interna). En esa medida, su estudio ofrece una oportunidad para replantear algunos problemas fundamentales para le teoría y la crítica literaria, en particular en lo relativo a las fronteras entre escritura, edición, lectura. Además, su estudio pone en evidencia la necesidad de reformular una nueva preceptiva para la teoría de los géneros literarios. (Zavala, 2004: 5)

Lauro Zavala en el ensayo "Fragmentos, fractales y fronteras. Género y lectura en las series de narrativa breve" (2004), utiliza el concepto de los fractales, estableciendo una metáfora de los relatos breves o minificciones, los cuales están integrados a textos mayores o forman parte de una unidad, pero no dejan de tener independencia textual.

La novela breve Diario del dolor (2004) de María Luisa Puga (1944-2004), es el último libro de toda su amplia producción publicada. Libro generoso e iluminado, el cual quería ser un manuscrito inspirado en sus conocidos "cuadernos" que acompañaron la vida de Puga: una vida literaria a través de fragmentos/relatos que se postergan en la esperanza.

\footnotetext{
${ }^{1}$ Sillón reclinable.

${ }^{2}$ Como afirma Roland Barthes en su libro El placer del texto: “¿Cómo leer la crítica? Una sola posibilidad: puesto que en este caso soy un lector en segundo grado es necesario desplazar la posición: en lugar de aceptar ser el confidente de ese placer crítico - medio seguro para no lograrlo - puedo, por el contrario, volverme su voyeur, observo clandestinamente el placer del otro, entro en la perversión; ante mis ojos el comentario se vuelve entonces texto, una ficción, una envoltura fisurada. Perversidad del escritor (su placer de escribir no tiene función); doble y triple perversidad del crítico y de su lector y así al infinito" (1973: 30).
} 
La fragmentación es un eje estructural y propone el carácter creativo de sus partes en la narración; esto se relaciona con imágenes de los fractales, formas creativas para percibir el orden y caos, objetos geométricos que aparecen en la naturaleza: "cuya estructura básica, fragmentada o aparentemente irregular, se repite a diferentes escalas. El término fue propuesto por el matemático Benoît Mandelbrot en 1975 y deriva del latín fractus, que significa quebrado o fracturado" ("Fractal": en línea). Los fractales surgen de la ruptura de un orden que se registra como una fracturación en el tiempo y espacio, semejante a lo que acontece en los relatos fragmentados y con sentido de autosimilaridad que se incluyen en Diario del dolor. Así existen referencias de los fractales en las artes plásticas, lo que corresponde a formas pensando en la armonía y la belleza, donde cada parte es similar al todo y da pie a un nuevo fractal:

El arte fractal tiene una estrecha relación con las matemáticas, sobre todo con la geometría, puesto que, como su nombre lo indica, retoma el concepto de fractal. Los fractales se basan en la repetición constante de patrones geométricos auto afines, es decir, que una porción es idéntica al todo. De esta manera, el fractal repite una serie de patrones hasta el infinito. (Sanguino, 2015: 1)

La fragmentación forma parte de un concepto literario integrado a la corporalidad textual del siglo XX y XXI, naturalizando gestos de secciones que fracturan un cuerpo. Ser fragmentario es dibujar el espacio de la escritura a manera de diseños que señalan un silencio entre los relatos. Una espera de lo que continúa, una espera que nos permite la libertad del autor y del lector en el acto de la lectura, siguiendo a Zavala señala:

la fragmentariedad que está en juego cuando se habla de novela fragmentaria consiste en la presencia simultánea de una fragmentación de la secuencia lógica y cronológica, y la presencia de elementos genéricos o temáticos en cada fragmento que garantizan la consistencia formal de un proyecto narrativo [...] Una vez más, el peso que se otorga a la unidad total por encima de cada fragmento es consecuencia de la herencia romántica que concede todo el peso del sentido al proyecto editorial del autor. Por otra parte, la frecuencia con la que un lector decide releer, comentar o incluso memorizar alguno de estos fragmentos como una unidad autónoma confirma la tesis dominante en la actual teoría de la recepción, en la cual se reconoce que la historia de la literatura la escriben las sucesivas generaciones de lectores, precisamente al reconocer aquello que les resulta significativo en su contexto de lectura. (2004: 11)

El concepto de fragmentariedad literaria se ha dispersado y legitimado, construyendo un nuevo canon de estrategias, formas e imágenes posibles que han sido ubicadas en la crítica literaria, pero el lector, siempre más allá de innovaciones y rupturas, descarta y pondera desde una subjetividad creativa. Entre el proyecto de escritura, así como los proyectos editoriales y la interpretación del lector, el texto sigue una profunda necesidad de experimentar, recreando identidades literarias en zonas fronterizas. En este contexto que intenta salir de lo binario, advertimos que la identidad de la novela corta se ha ubicado entre el cuento y la novela, sin un espacio propio mientras su completitud está más allá de esas dos orillas. Definición que se expande: extensión, economía a través de un solo narrador, pocos personajes y una línea temática; en cambio la diversidad surge en la estructura y las formas narrativas mediante una serie de figuras que se repiten y se bifurcan en las posibilidades de escritura - fragmentos que el autor coloca para poner un límite, un corte, un silencio-, mientras que en el acto de lectura se reproducen las posibilidades una y otra vez ad infinitum. Lo que el lector recibe es la impronta de un instante que se prolonga a través de imágenes que se multiplican a partir de un 
patrón. La novela corta fragmenta el espacio y el tiempo de lo que se evoca como realidad literaria en un transcurso de lo narrado, es decir, acontece la transgresión de lo real de un modo evidente y necesario. Guillermo Fadinelli en su ensayo "El orden perdido" afirma: "yo me inclinaría por definir la novela breve como un relato que no va más allá de cierta extensión y que se puede comprender como un mundo en sí mismo" (2014: 44); su postura en relación a la novela corta nos permite ver un punto de vista oblicuo:

Me agrada pensar que poseo una teoría porque mis intuiciones o impulsos primarios detestan el orden impuesto. Y si se trata de ir en contra también de mis impulsos soy un experto en oponer resistencia. Lo hago así porque sé que tarde o temprano perderé la absurda batalla. Por ello mismo no podría definir el cuento breve como un género rígido: el cuento breve es el relato de una limitación y su puesta en página es lo único que importa [...]. Me rehúso a escribir una novela breve como parte de un plan premeditado. Las explicaciones y los géneros literarios, en mi opinión, tocan a la puerta una vez que la muerte ha hecho su aparición y la obra se encuentra ya en manos de los lectores. (2014: 47)

Este crítico se refiere a la muerte del autor, pero yo creo que es un proceso donde el autor no desaparece, sino más bien quiere dejar su huella, su voz, su corporalidad y decide que la figura autorial es esencial a través de lo autobiográfico; no obstante, el lector afirma $a$ posteriori la recepción de un modo privilegiado. En el ensayo titulado "Exploración", Alberto Chimal enfatiza el acto de leer como una forma de percibir este género en la exploración del mismo acto de escritura, toma en cuenta el impulso ${ }^{3}$ y la poderosa atracción de la narración breve para ejercer la libertad del autor y del lector, quienes juegan a soltar y diluir el eje narrativo para después recuperarlo en espacios textuales fragmentados que tomamos entre las manos, donde todo fluye y se escapa:

El poder de la novela corta es, pues, el de explorar el mundo a medida que se le crea; distanciarse de la anécdota, o, mejor dicho, mantenerla como un centro al que se le puede volver luego de hacer paseos por la vida previa de los personajes, por los sitios aledaños a aquellos donde incurre la acción, por las impresiones sensoriales disponibles y sus consiguientes percepciones. Así, el mundo de la novela corta se crea — casi invariablementepor inducción, que es el mismo proceso por el que al menos un escritor aspirante emprendió el aprendizaje de la novela corta. (2014: 40)

No obstante, el rigor de la prescriptiva literaria ha limitado qué textos pueden incursionar dentro de la novela corta - dentro o fuera de parámetros que ya viven en situaciones porosas o liminales. Corpus textual que se amplía a través de las estéticas de distintos autores, mediante "el espectro de un canon" pleno de diferencias que se desordenan para crear otras formas; lo que no solo sucede en un proceso de continuidad y ruptura, pues sería limitado

\footnotetext{
3“El descubrimiento de todas estas características de la lectura de novela corta me llevó, desde luego, a intentar lograrlas a la hora de escribir: a descubrir los mecanismos (o los recursos, o las herramientas; la metáfora que se elija es lo de menos) por los cuales se podía llegar a provocar los efectos que encontraba como cualquier otro aprendizaje que se emprende por cuenta propia, hacer esto fue (y aquí sí importa la metáfora) una exploración: la averiguación de lo previamente desconocido en un conjunto de saberes que puede entenderse como un campo, una extensión en la que las ideas y posibilidades cercanas entre sí por afinidad o alejadas por contraste, y en la que lo mismo hay terrenos llanos: formas evidentes y fáciles de percibir y replicar, y otros agrestes: las porciones de la escritura difícil" (Chimal, 2014: 40).
} 
pensarlo así. ${ }^{4}$ El espectro de lo literario se bifurca como si de una mágica estructura fractal se tratara: forma perfecta y caótica.

En México, toma lugar un entrañable proyecto titulado Una selva tan infinita. La novela corta en México (1891-2014), coordinado por Gustavo Jiménez Aguirre, el cual inicia en el 2009, continúa en el 2012, y el último libro se publica en el $2014 ;^{5}$ tres tomos que puntualizan una historia de la novela corta desde el rigor y el placer de la lectura, así como de la liminalidad, la recepción, la crítica, y la concepción literaria. Según Rosa Beltrán, en el prólogo "Por un género mayor", se enfatiza una defensa y reconocimiento de este género menor y ratifica la posición del escritor, el crítico y el lector como eje del trabajo de investigación:

Se trata de un trabajo excepcional y abarcador que sin embargo evita la tentación de lo faraónico: es decir, un proyecto anti Julio Jiménez Rueda y su Antología de la prosa en México, 1931, y anti Antonio Castro Leal y La novela de la revolución mexicana, donde cabía todo, y por eso mismo, como dice Gustavo Jiménez, no se veía nada. No discuto la importancia de estas obras. Pero los actuales criterios de selección y el momento histórico que vivimos, un momento en el que ya no es importante reunir todo lo existente para definirnos como país, nos permite ver el árbol perdido en el bosque y hacer honor al sentido del título, tomado de una frase de Jorge Luis Borges que alude al corazón de este proyecto: "Una vez hubo una selva tan infinita que nadie recordó que era de árboles”. (2014: 11)

\section{Autora y lectora en un mismo cuerpo}

Puga es una autora que he reflexionado en el libro Palabras Vivas. Ensayos de crítica literaria entorno a María Luisa Puga (2016) y en el ensayo titulado "La bitácora de la enfermedad y los males del cuerpo en Diario del dolor", en Las seducciones literarias (2014). En ambos documentos, he revisado diferentes líneas de su obra, su estética, sus obsesiones, y cómo fue construyendo su producción literaria en torno a varios temas clave como la memoria, la identidad social, nacional y existencial; así como la extranjería, lo autobiográfico, el cuerpo, los personajes femeninos, entre otros asuntos que brindan una valiosa coherencia a toda su obra.

A Puga, una mujer exigente como lectora y siempre de sonrisa amplia, la conocí en los años noventa en un taller de cuento en Pátzcuaro, Michoacán, México. Ella fue una viajera y

\footnotetext{
${ }^{4}$ El mismo autor comenta: "Cuando lo excepcional se convierte en la norma (o más exactamente, cuando la ruptura se convierte en una tradición de ruptura) es necesario reformular el concepto mismo de canon, y reconocer las estrategias de lectura que hacen posible la escritura de textos que sólo son excepciones desde la perspectiva de las preceptivas originarias" (citado por Zavala, 2004: 7).

${ }^{5}$ Gustavo Jíménez en "NC/2014: algunas tareas cumplidas" afirma: "alentaron la reflexión genérica e iniciaron la edición de veintiocho obras para actualizar la lectura y la comprensión en un corpus originalmente publicado desde 1872 hasta 1922. [...] La segunda colección de La novela corta. Una biblioteca virtual se llama «Novelas en Campo Abierto. México: 1922-2000» y empezó a circular en noviembre del 2012. [...] «Novelas en Campo Abierto» no se propuso construir un canon de la novela corta del siglo XX, tampoco pretendió agotar las tendencias o las obras de las figuras emblemáticas del género. El proyecto inicial se redujo por limitaciones presupuestales, algunas negativas de los titulares de los derechos y la realidad laboral de un grupo de mediadores académicos entre el público de la red y la veintena de obras que, finalmente, se pusieron en circulación con el mayor esmero editorial posible. Aun así, todo se hizo entre todos, desde nuestra casa de trabajo" (Jiménez, 2014: $16,20,21-22)$.
} 
decidió su propio exilio dentro de su propio país, siendo una "fuereña"; en 1985, con la intención de escribir y dar talleres de creación literaria, partió hacia Zirahuén, Michoacán, lugar que elegiría como refugio para contemplar el mundo. En 1996, obtuvo el Premio Nacional Juan Ruiz de Alarcón. Su obra la integran textos como: Las posibilidades del odio (1978), Pánico o peligro (1983), Cuando el aire es azul (1980), La forma del silencio (1987), Antonia (1989), Las razones del lago (1991), La viuda (1994), La reina (1995), Inventar ciudades (1998) y Nueve madrugadas y media (2002); así como libros de cuentos: Inmóvil sol secreto (1979), Accidentes (1981), Intentos (1987) y De intentos y accidentes (2001); y libros para niños: El tornado (1985), Los tenis acatarrados (1991), La ceremonia de iniciación (1994) y A Lucas todo le sale mal (2005), y, finalmente, Diario del dolor (2004) que nos conduce a una necesaria valoración y lectura de toda su obra por su sentido de epitafio regresar hacia lo que se fue construyendo a través de una memoria personal y una memoria literaria.

El sentido autobiográfico lo encontramos en toda su narrativa, evidente en su $D e$ cuerpo entero (1990), libro que reúne ensayo, escritura y viajes para cifrar el camino entre escritura y extranjería, es decir, la estrecha relación que estableció entre escribir y viajar como una forma de conocerse a sí misma y a los otros; otredad que es evidente entre la narradora y los personajes, como sucede también con Dolor (García Argüelles, 2016). ${ }^{7}$ En sus narraciones y cuentos aparecen personajes que exploran la autoconsciencia y la transformación de la voz narrativa y de las protagonistas; sus narradoras frecuentemente se identifican con la figura autorial, retomando el proceso de la figura de la escritora, alter ego de Puga. En Diario del dolor esto sucede de un modo puntual y punzante, a pesar de que solo una vez se menciona el nombre de ella justo a la mitad de la novela, en un cruce entre la ficción y la biografía, llamada también autoficción. No es la intención de Puga escribir una autobiografía novelada sino una novela breve autobiográfica consciente de las herramientas que han nutrido sus ficciones. La voz narrativa descifra la identidad de la escritora en la metaficción y la enunciación de la memoria entre un antes y un después de la enfermedad al ser paciente de una clínica de salud, siendo una extranjera de la salud (Sontag, 1996); sin embargo, la salud se halla en la escritura y la lectura. Su historia privada y todas las formas de exorcizar los dolores de su vida se transfiguran en el acto de escritura, como vemos en los relatos "48. Hablemos en serio" y "34. Pasos dificultosos e inevitables":

\footnotetext{
${ }^{6}$ Palabra muy mexicana que Puga acuñó para referirse a una situación de extrañeza dentro de su propio país, a diferencia de extranjería; otra forma de mirar a los otros e intentar sentirse parte de ese otro contexto regional, cultural, e incluso lingüístico, término que refiere en su texto Crónica de una oriunda del kilómetro $X$ en Michoacán (1995).

${ }^{7}$ En este trabajo afirmo: "La búsqueda de la palabra es también el encuentro con el silencio y la soledad, silencio que surge al otorgarle voz a los otros, mientras contemplamos la realidad que nos circunda" (2016: 21). La relación de la narradora y la protagonista es de otredad, pero el otro desde la perspectiva de la voz narrativa ubica una correspondencia amorosa, para lo cual escribo una cita de Mijaíl Bajtín: "Por lo demás, a pesar de la permanente interpelación que permea nuestra actuación en el mundo, la influencia del otro sobre mí es, en un principio, favorable y benigna: el otro me otorga la primera definición de mí, de mi cuerpo, de mi valor y lo hace en los términos amorosos y plenos de una tensión emocional positiva irradiada por la persona que nos recibe por primera vez en el mundo. Además, la posición del otro es decididamente ventajosa si la comparo con la mía: el otro posee un excedente de visión sobre mi persona y el mundo, al percibir todo aquello que yo no puedo ver desde mi posición única. El amor estético, que permite dar al otro una conclusión específicamente estética, es parte imprescindible de la relación con el otro" (Bajtín, 2000: 19).
} 
Me dolía por aquí y por allá, pero a lo largo de los años aprendí a capotearte sin tener que nombrarte. Desde 1985. Cómo nos evitamos hasta octubre del 2001. Tú, porque yo a los doctores los comencé a ver mucho antes. Y sí tenía algún tratamiento, el que fuera, me sentía a salvo. Sociedad civil con voz, aunque siempre me estuviera doliendo algo. [...] En algunos de esos cuadros estoy yo. Seré yo cuando digan: María Luisa Puga, pasillo (?) y entonces ya no habrá marcha atrás. [...] Y ahora yo soy parte de ella. Me quiero arrancar y no puedo. Ya no tengo brazos, cara o piernas. Ni siquiera silla de ruedas. Estoy aquí y allá afuera quedó mi vida. Dolor, te extraño. Ni la pasamos tan mal. Aquellas mañanas silenciosas en la casa, toreándonos para no tropezarnos. Casi las puedo ver con nostalgia, lo que pasa es que esto es tan grande y tan desconocido que no me atrevo a perderlo de vista. [...] ¿Es la ciudad de la enfermedad ésta? ¿La ciudad de la pausa? ¿El famoso stand by? (Puga, 2004: 48-49, 33-34)

En Diario del dolor el contenido autobiográfico es un proyecto que "pierde el orden", pues la fragmentación del cuerpo textual y del cuerpo físico parece seguir una misma línea, un mismo propósito entre la pausa y la respiración para después tener consciente las partes del cuerpo y las partes del texto. La ficcionalización a través de la novela corta alude a un juego irónico que humaniza la figura del dolor ante la pérdida de integridad del cuerpo; nombrando y subvirtiendo el dolor hacia una reconciliación espiritual y emocional e, incluso, literaria, donde las dolencias del cuerpo adquieren un nombre propio en la ficción, mientras el cuerpo femenino pierde su identidad. Esta es una novela frágil entre las manos, podría anunciar la facilidad de lectura y la agilidad del tiempo al leerla, pero la brevedad también anuncia una profunda herida, lo que se puede confirmar en textos como El apando de José Revueltas, en Salón de Belleza de Mario Bellatín, Los adioses de Juan Carlos Onnetti o Agua Viva de Clarice Lispector, por mencionar libros de intensidad valiosa.

Diario del dolor fluye fragmentariamente, se configura en el recorrido de cien breves relatos, en medio de silencios y vacíos entre uno y otro, con un número y un título para narrar distintas vivencias, objetos y días. El libro incluye tres discos compactos leídos por la misma Puga, los cuales me parecen indispensables al reconocerme como una lectora que además escucha. Este libro pequeño tiene como fin compartir la experiencia de la enfermedad de la autora de artritis reumatoide, ${ }^{8}$ pero también tiene la idea de sanar a los demás, ya que la misma autora brindó a la Secretaría de Salud y al INBA (Instituto Nacional de Bellas Artes) su distribución en las clínicas. En la siguiente entrevista a Rubén Mejía y Saúl Juárez, poco

\footnotetext{
8“La artritis reumatoide (AR) es una enfermedad inflamatoria crónica, de naturaleza autoinmune, caracterizada por la afectación simétrica de múltiples articulaciones y la presentación de diversos síntomas generales inespecíficos y manifestaciones extraarticulares. Librada a su evolución natural y en ausencia de tratamiento adecuado, la enfermedad puede causar, en fases avanzadas, importantes limitaciones físicas, así como un marcado deterioro de la calidad de vida. La AR se manifiesta típicamente por dolor, tumefacción y rigidez o dificultad de movimiento en diversas articulaciones pequeñas y grandes. Los síntomas generales, que a veces preceden a las manifestaciones articulares y tienden a persistir durante toda la evolución del trastorno, incluyen básicamente cansancio, sensación de malestar, fiebre ligera, inapetencia y pérdida de peso corporal. Las posibles manifestaciones extraarticulares, que suelen presentarse cuando la enfermedad ya está establecida, afectan principalmente a la piel, los vasos sanguíneos, el corazón, los pulmones, los ojos y la sangre. La AR es mucho más frecuente en el sexo femenino que en el masculino y suele aparecer en personas adultas mayores, pero puede iniciarse en cualquier etapa de la vida y afectar a cualquier persona, con independencia de la raza, el sexo y la ocupación. El síntoma inicial más frecuente es la rigidez articular matutina (sobre todo en las articulaciones de manos y pies), que se presenta tras el reposo nocturno y comporta una notable dificultad de movimiento. La rigidez matutina se puede acompañar de cansancio, fiebre, pérdida del apetito y debilidad muscular, un cuadro que a veces aparece semanas o meses antes que el dolor y los signos que denotan inflamación articular, es decir, hinchazón, calor y enrojecimiento en las articulaciones comprometidas" (ConArtritis: en línea).
} 
después de la muerte de Puga, Saúl Juárez (quien en ese entonces era el titular del INBA) recuerda sobre Puga y este proyecto de grabar su voz cuando se encontraron en Páztcuaro por última vez:

Por su parte, Saúl Juárez, titular del Instituto Nacional de Bellas Artes (INBA), y a su vez colega de la escritora y con quien mantuvo una relación de amistad, dice vía telefónica que tal vez exagera al decir que Puga fue la primera coordinadora de un taller literario en la red, pues no ha conocido otro caso así. [...]

"En una ocasión nos encontramos en Pátzcuaro, y en su camioneta me puso un casete, ahora convertido en $\mathrm{CD}$, en el que se escuchaba su voz en torno a su relación con el dolor, y de ahí salió la idea del libro y compartir ese material con la gente que tiene esa relación obligada con el dolor".

Al director del INBA se le ocurrió llevar el volumen y el disco a la Secretaría de Salud, lo acompañaron Puga y Levín. El secretario, Julio Frenk, acogió la propuesta.

El programa empezaría en febrero o marzo de 2005 con la escritora y se volvería a presentar el libro en los primeros meses de este año. La idea es que el libro se distribuya en las clínicas, "pero desafortunadamente ya sin ella para leer, explicarlo o comentarlo".

Y acota: "Creo que la gran enseñanza del libro es que también el dolor te invita a ver al mundo, a los demás, de una forma distinta a como suelen tenerla quienes estamos sanos". (Moreno Valenzuela: en línea)

La estructura y la generosidad de este proyecto editorial es un ejercicio de síntesis y de reflexión en torno al relato corto, medidos con regla que van de diez a veinte centímetros cada uno; el lector decide leer los relatos en el orden autorial o elegir un orden distinto. En este sentido, la palabra relato es un comodín de aquello que no se ajusta a lo que es un cuento, una manera de generalizar este tipo de textualidad: "En lengua española, el término relato ha sido utilizado ya sea para referirse a algo más que un cuento (un cuento experimental), a algo menos que un cuento (una narración sin valor literario) o algo diferente a un cuento (ya sea un texto híbrido, un cuento muy extenso o incluso un poema en prosa)" (Zavala, 2004: 8).

\section{El arte de la memoria: el diario y la autobiografía}

La memoria es una estrategia narrativa privilegiada en Puga, podría decirse que es la materia para construir sus novelas y cuentos, tanto en relación a sus temas y a la manera de moldearlos. Diario del dolor repara en la vida de la autora y en su forma de escribir, ensayando la consciencia del arte de la memoria. La memoria del lector y la memoria del autor se conectan entre el recuerdo del pasado y el presente narrativo. Hay un imprescindible lugar de la memoria histórica si pensamos en 1968, por ejemplo, en su consciencia social y compromiso de la situación política en México, pero también se esparce la memoria literaria y sus lecturas en los autores que cita, y desde luego, la memoria personal a través de un proceso cognitivo que permite reconstruir la identidad del sujeto femenino y la identidad de los objetos, de las palabras — pasando por un proceso de contemplación, fragmentación y aprendizaje - . La forma de conocer el mundo e intentar cambiarlo es a partir de la memoria verbal, auditiva, visual, incluso, la sensorial, es decir, todo se conjunta para descifrar su visión de mundo y de los otros, de los espacios que mira desde las ventanas para transmutar el cuerpo y la memoria en un sentido estético. El proyecto literario de Puga necesita evitar el olvido de los acontecimientos, de los viajes, de la familia, de la ausencia de las personas como su madre, incluso, a sí misma. En el ensayo «El delicado fulgor de las cosas»: María Luisa 
Puga, Virginia Woolf y la interconectividad" de Rebecca Bowman, quien recupera el espacio, el tiempo y los personajes en alusión a textos y estilo de Virginia Woolf, nos dice:

En otros textos de Puga, el hecho de que lo que se cuenta es recuerdo, que el adulto recuerda la niñez, o una persona tiene muy presente a sus familiares muertos también crea una conexión entre el presente y el pasado, entre el pasado y lo que es en ese momento el futuro. Además se indaga en el pasado para entender el presente y para decidir el futuro. Esto también crea cierta calidad de tejido que se parece a la de Woolf. (Bowman, 2010: 87)

Su último libro es un preámbulo para recordar el sonido, las sensaciones, el tiempo y espacio de una construcción literaria como un registro de lo vívido ante la inminencia de la muerte. Recordar la bitácora de la enfermedad se ciñe a la edificación de relatos breves en torno a cada día sin una cronología precisa, días que pueden intercambiarse en la forma del diario literario entre la privacidad y lo íntimo. En los relatos "42. ¿Cómo, pues vine a dar hasta aquí?” y “45. Para distraerme, imagino":

La extrañeza a ratos me azota la cara. Es cuando me descuido, cuando me dejo ir en finta de un tiempo normal. NORMAL. Qué bárbaro, cómo que normal. No hace ni seis meses que caminaba. Con mucho dolor, no digo no, pero me podía trasladar de un lugar a otro. Cierto, lo primero era un lugar en dónde sentarme y cuando me ponía de pie cojeaba espantosamente, pero esas eran las transiciones. No se llamaban artritis ni cadera. No sabía nada de mis huesos pegados. Todo era NORMAL. Fueron las malhadadas radiografías las que me mostraron mi verdadero rostro (esqueleto, digo. Ese esqueleto limpito que decía el otro doctor). Lo que pasa es que normal es siempre todo. Nadie, hasta donde sé, vive en estado de excepción. [...] ¿Cómo será verme arrebatada de mí? Como caer en prisión o encontrarte en un exilio no voluntario. Sin la identidad de siempre por más que esté presente como recuerdo. Porque ahí estará mi cuerpo, mi memoria, mis hábitos ahora huecos, algunos de mis objetos (cuaderno, pluma, a lo mejor computadora), pero ya no seré la misma. Quizá lo único que permanezca idéntico en todo sea Dolor. Por lo menos al principio, después quién sabe. (Puga, 2004: 42-43, 45)

La enfermedad pone a la escritora frente a un antes y un después de la escritura, un antes del cuerpo erguido / un después del cuerpo deformado, discapacitado. El aspecto fragmentario y los fractales a través de la memoria se desplazan en el presente y el pasado, mientras el futuro en relación a la enfermedad y la corporalidad viva en el texto: "El cuerpo es como agua que se escurre entre las manos imaginarias del conocimiento. Si bien se destaca su materialidad última, justamente es ella la que no habla. El cuerpo limita el silencio." (Parrini, 2008: 18-19). La naturaleza de la memoria reside en el cuerpo - evocamos la historia que somos y creamos un relato, en medio está el cuerpo físico, su materialidad irrevocable- - El tiempo es testigo de la pérdida de movilidad y la capacidad física corporal mientras que se recupera la identidad y la memoria en diferentes instancias de la enunciación: el yo que recuerda su vida, el yo recordado en la ficción y la posibilidad de tejer un recuerdo en la lectura.

En Diario del dolor, la representación del cuerpo y la identidad se presenta a través de un proceso de desplazamiento de la voz de la narradora/autora a la voz de Dolor como personaje, por eso "diario del dolor" y no "diario de María Luisa Puga". Esta ambigüedad en la narración se va despejando hacia la ficción y la reescritura de la memoria para transmutar el lado negativo de vivir enfermo e intentar sanar a todos aquellos que lean esta novela. La memoria y la experiencia autobiográfica siempre emerge en su textualidad, afirma Irma López 
en su ensayo, "Re/composición del cuerpo/texto en diario del dolor", quien ha trabajado las conjeturas del yo en la literatura femenina:

La escritura autobiográfica en la ficción puguiana detalla los esfuerzos continuos y complicados que los personajes novelescos realizan para reconstruir o rescatar una identidad personal afectada por crisis que generalmente anticipan estados nuevos de autoconciencia. [...] el texto examina la memoria como dominio del dolor corporal, como protección íntima y como producción de arte, pero, el libro también explora la manera en que la cultura responde a las enfermedades, en un intento de puntualizar el lugar que ocupa el cuerpo enfermo en la sociedad de su tiempo. (2006: 233-234)

La forma del diario da estructura a los relatos conectados en la novelización y la voz de la narradora — su cuerpo, su consciencia-. El diario es una forma semejante a los cuadernos escritos a mano que acompañaron a Puga en toda su producción literaria. Las manos para esta autora son una forma de fetiche, legitimidad del acto creativo, las cuales aparecen deformadas por la enfermedad y le arrebatan la posibilidad de seguir escribiendo. Los cuadernos inspiran este libro jugando con la memoria. Afirma Puga en De cuerpo entero (1990):

"El cuaderno es como mi grabadora, mi cámara fotográfica, mi consciencia. La sala de gimnasia de la escritura; el lugar de las reacciones secretas; el poder juzgar el mundo", y luego agrega "Se llega ahí para ver qué ha pasado en ese interactuar con el mundo. Para sacar las voces de lo de afuera y examinarlas con alma. Para reordenar las vivencias. (Puga, 1990: 2122, citado por López, 2006: 239)

Los cuadernos son mencionados en varios de sus novelas, pero en Diario del dolor para mí es un homenaje a estos compañeros que le prodigaron "recuerdos" y fueron transformándose en su narrativa, que además fueron sus diarios privados; que brindaron luz ante la enfermedad. Un cierre magistral de su vida literaria, siendo autora/narradora y mujer/persona sin dejar el proceso de consciencia que confluye en el arte de la memoria para reescribir el pasado, el presente y un futuro que expanda esperanza. En Puga no hay ausencia de memoria, todo lo contrario, los cortes y silencios de los relatos no es falta de palabras ni olvido, sino un impase entre la vida y la ficción, un breve silencio fragmentando la espera y dar sentido a través de fractales que se repiten, recuerdos que se viven y se reescriben:

Dolor siempre se ha mostrado escéptico ante el cuaderno. Doble esfuerzo, parece decir con la mirada. O peor aún: Esfuerzo inútil. Se podría decir que ante la escritura Dolor esgrime una actitud misógina. En ese terreno ambos nos damos la espalda. Yo me encorvo ante el cuaderno; él, sepa qué hace. El cuaderno sirve para inventar las palabras con las que voy a decir o a decirme. O sea, sirve para ensayarlas. Hágase de cuenta que práctico ante un espejo. ¿Se ha visto algo más tangible, más concreto, más sabroso que la escritura manuscrita? No hasta donde yo sé. Es como ir caminando por una calle y de pronto ver la fachada de una casa invitadora, como hecha a medida para uno. Si no la mete uno en el cuaderno, se pierde para siempre. Es más importante meterla en el cuaderno que entrar a la casa. (2014: 35)

El cuerpo fragmentado y la novela fragmentada establecen una conexión esencial. La memoria se vuelve silencio y vacío ${ }^{9}$ que se reconstruye en la forma del diario para ir

\footnotetext{
9 "La voz narradora se apaga durante períodos insostenibles y en esos vacíos verbales se esfuma tanto su persona como la escena que está tratando de evocar. Este titubeo narrativo, sin embargo, no lo sabemos directamente del personaje, sino que la estructura misma de la obra nos ofrece la pista para intuir en dónde inicia y termina la ola devastadora que cubre al cuerpo doliente. Los intervalos entre un fragmento y otro constituyen la clave para
} 
conjeturando presente, pasado y futuro de un proceso de transformación del cuerpo y del texto hacia un tratamiento irónico. El género del diario se expande, pues más allá de la "privacidad" se abre al lector la vida del autor, $y$, además, se da forma a un diálogo entre la narradora y Dolor. Las palabras nostalgia, memoria, olvido, recuerdos, extrañar/extrañarse van dando pausa a la narración, a las formas posibles vecinas, autobiográficas e íntimas que dialogan en el libro clásico, La autobiografía de George May. Un diario se vuelve público al proponerse como texto literario, es decir, se modifica la redacción exclusiva para quien lo escribe, continúa su sentido de intimidad, pero no ya de privacidad. ${ }^{10}$ La memoria de los objetos es una manera de extender la situación corporal de imperfección al caos intencional e intenso de la novela corta, ridiculizando en situaciones lúdicas e irónicas de la narradora juega con Dolor, aludiendo a la integridad y la torpeza, como vemos en la cita del relato "58. Babotazo":

Dícese del golpe o golpes que uno se da por babotas, por no prestar atención, por creer que los objetos son dóciles a la costumbre. Ilustraré: con el bastón pesco una olla de tamaño mediano. La descuelgo y en el momento en que la estoy bajando dejo que por un segundo mi atención se vaya por otro lado. ¡Babotazo de olla contra rodilla En estos casos se llora de rabia, además de dolor. Los objetos, luego de golpearte, se precipitan al suelo muertos de risa. (2014: 59)

El proceso de la metaficción es otra estrategia recurrente de Puga en la figura de la escritora, quien constantemente reflexiona sobre sus dudas, la forma, el recuerdo para escribir sus novelas, como sucede también en la novela de Antonia (1989), enlazando el viaje y el convertirse en escritora en su viaje a Londres en la búsqueda de Virginia Woolf; o en Inventar ciudades (1998), donde dice "Porque eso es lo que me pasa cuando leo mis cuadernos: soy yo y no soy yo. Soy un dolorosamente ya no" (1998: 109).

\section{Conclusiones: ¿Dónde quedó la novela?}

La metaficción y la figura de la escritora en voz de la narradora juega con diferentes estrategias e imágenes como la ironía y la intertextualidad, creando juegos/refugios de la escritura que prefiguran una memoria del lector, ${ }^{11}$ quien busca un orden a seguir en medio del caos de los recuerdos: "Porque antes de todo esto, yo siempre traía una novela en la cabeza, rodándome como mosca. Lo que me rodeaba se convertía en parte de esa novela, desde el

detectar y evocar la aflicción tremenda que la acompaña y que se agudiza en ocasiones. Las cien relaciones breves del texto como entidades autónomas, que no se organizan o entrelazan a partir de un orden de causa y efecto, abren huecos en el andamio de la narración y recrean la ausencia de voz referida a la insuficiencia del lenguaje que encuentra el ser humano para nombrarse y detallar su agonía. (López, 2006: 245)

${ }^{10}$ El género del diario lo trabajé anteriormente. Según Hans Rudolf Picard, en su ensayo "El diario como género entre lo íntimo y lo público": "Es revelador el hecho de que quien diera al diario el nombre de «journal intime», como denominación genérica, no fuera un diarista sino un editor. La expresión de «journal intime», cuyo éxito se aplica naturalmente por el hecho de ser, desde el punto de vista semántico, una determinación delimitativa de la palabra «journal» —en el sentido periódico — aparece por primera vez en el título bajo el cual en 1982 el editor E. Scherer publicó una parte del diario de Henri Fréderéric Amiel [...] El paso del status privado del diario a su status público es un acontecimiento importante, tanto desde el punto de vista de la historia de las formas literarias como del de la ontología de la Literatura" (Picard,1981: 118).

${ }^{11}$ La figura del lector guarda en su memoria un rostro de Puga ineludible, el que se continúa en toda su obra: "Los desplazamientos y variantes del ser que los lectores identificamos en su novelística nos advierten un yo escindido que (re)construye su mundo y la imagen propia repitiendo su presencia y dispersión en un juego de cambios y reflejos que sintetizan diferentes etapas de la (de)formación de la identidad de la mujer/escritora: María Luisa Puga" (López, 2006: 240). 
batir de un ala, hasta un lejano ¡Panchooo¡, emitido por allá en el bosque. La traía, sí, como ahora traigo a Dolor, a manera de aureola. No había manera de escabullirse" (Puga, 2004: 19). La narradora se presenta, además, como lectora de sus propios cuadernos y de su libro. En Lo que le pasa al lector también de Puga, Demetrio Anzaldo comenta:

Este texto se ha dejado a la deriva por un canon literario mexicano que no lo quiso ni supo leer a tiempo. Pasando por alto o descontando burdamente por la "crítica especializada" es un escrito que debiera ser revalorado con justicia y libertad. [...] Su entrega a la escritura la conduce a ponerla en práctica en cada una de sus manifestaciones. En Lo que le pasa al lector se aprecia su labor como crítica literaria al escuchar una voz autorial que cuenta, que se amolda acompasadamente a la energía, la materia, la realidad, el silencio, el vacío, el habla de la vida, para nutrir a su voz literaria, a su hablar, de un sentido más correcto. [...] El lector es un espectador que de pronto puede detener el acontecer y con su imaginación cambiarlo. Con su lenguaje propio. (Anzaldo, 2016: 181-182)

Esta cita parece coincidir con la visión de Lauro Zavala ${ }^{12}$ sobre el relato y la novela corta, en medio de fragmentos y fractales, en medio de silencios, de libertad literaria y un gesto de sanación. La intertextualidad se teje desde entre el texto autobiográfico y la ficción, en la mención de escritores como Borges, Kafka y Cortázar. En el relato "38. La perspectiva" se sugiere la humanización de figuras y categorías literarias para construir la novela, es como si a medida que el cuerpo de la narradora fuera perdiendo identidad, la novela fuera nutriéndose y tomando forma, tomando vida:

Como un atardecer inexorable, la perspectiva cobra cuerpo. Me duele todo, para qué especificar qué. Siento que los huesos chillan pidiendo atención. Dolor anda cabizbajo, ni siquiera participa de mis abruptos entusiasmos. Ha entendido antes que yo que la operación es ineludible. Lo que yo creía libertad no era más que un postergamiento muy mexicano: Mañana hablo. No contestan. Se me hace que Nutrición no existe. Dolor opina lapidario: Claro que existe, quién más pudo haber inventado a Kafka. (Puga, 2004: 38)

\section{Bibliografía}

ANZALDO GONZÁLEZ, Demetrio (2016): "Una asertiva palabra que resurge en la historia: el hablar real de María Luisa Puga en Lo que le pasa al lector". En Elsa Leticia García Argüelles (coord.), Palabras vivas. Ensayos de crítica literaria en torno a María Luisa Puga. México, Universidad Autónoma de Zacatecas/ Instituto Zacatecano de Cultura: 159-187.

BAJTíN, Mijaíl Mijáilovich (2000): Yo también soy (fragmentos sobre el otro). Selección, traducción, comentarios, prólogo de Tatiana Bubnova. México, Taurus.

\footnotetext{
${ }^{12}$ Según Lauro Zavala, la ironía y el aspecto lúdico forman parte de esta saga de la construcción de la minificción, y otros relatos cortos que integran la serie que integran un texto mayor: "El surgimiento del término minificción es consecuencia directa de este nuevo contexto de lectura, donde las posibilidades de interpretación de un texto exigen reformular las preceptivas tradicionales y considerar que un género debe ser redefinido en función de los contextos de interpretación en los que cada lector pone en juego su experiencia de lectura (su memoria), sus competencias ideológicas (su visión del mundo) y sus apetitos literarios (aquellos textos con los cuales está dispuesto a comprender su memoria y a poner en riesgo su visión del mundo). [...] Aquí es conveniente señalar que los textos que conforman una serie de cuentos integrados están escritos teniendo en mente su relación entre sí, de tal manera que en conjunto adquieren una clara unidad estructural. Por esta razón algunos estudiosos han propuesto llamarlos también cuentos enlazados (Enrique Anderson Imbert) o cuentos moleculares (Slawomir Dölezel)" (Zavala, 2014: 8-9).
} 
BARTHES, Roland (1973): El placer del texto. México, Siglo XXI

BOWMAN, Rebecca (2010): “«El delicado fulgor de las cosas»: María Luisa Puga, Virginia Woolf y la interconectividad". Divergencias. Revista de Estudios Lingüísticos y Literarios, vol. 8, núm. 2 -Sección Especial- (2010): 85-91.

ConArtritis (Coordinadora Nacional de Artritis): http://www.conartritis.org/todo-sobreartritis/que-es-la-ar/que-es-la-artritis-reumatoide [26/01/2020].

FADANELLI, Guillermo (2014): "El orden perdido". En Guillermo Jiménez Aguirre, Una selva tan infinita. La novela corta en México (1891-2014) III. México, Universidad Nacional de México: 43-48.

"Fractal": https://es.wikipedia.org/wiki/Fractal [30/01/2019].

CHIMAL, Alberto (2014): “Una exploración”. En Guillermo Jiménez Aguirre. Una selva tan infinita. La novela corta en México (1891-2014) III. México, Universidad Nacional Autónoma de México: 35-42.

BELTRÁN, Rosa (2014): "Por un género mayor". En Guillermo Jiménez Aguirre, Una selva tan infinita. La novela corta en México (1891-2014) III. México, Universidad Nacional Autónoma de México: 7-12.

GARCÍA ARGÜELLES, Elsa Leticia (2014): "La bitácora de la enfermedad y los males del cuerpo en Diario del dolor, de María Luisa Puga". En su libro Las seducciones literarias. Representaciones de la literatura femenina en América. México, Texere: 17-41.

---, coord. (2016): Palabras vivas. Ensayos de crítica literaria en torno a María Luisa Puga. México, Universidad Autónoma de Zacatecas. Instituto Zacatecano de Cultura.

LÓPEZ, Irma (2006): "Re/composición del cuerpo/texto en Diario del dolor". Revista Anuario de Letras Lingüística y Filología, vol. 44 (2006): 234-253.

PUGA, María Luisa (1989): Antonia. México, Grijalbo.

--- (1990): De cuerpo entero. México, Universidad Nacional Autónoma de México/Eco.

--- (1991): Lo que le pasa al lector. México, Grijalbo.

--- (2014): Diario del dolor. México, Alfaguara / Universidad del Claustro de Sor Juana / Consejo Nacional para la Cultura y las Artes.

MAY, Georges (1982): La autobiografía. México, Fondo de Cultura Económica.

MORENO VALENZUELA, Rubén (2006): "María Luisa Puga dejó dos novelas terminadas". Entrevista con Raúl Mejía. En su blog: "Rancho las voces. Revista de Arte y Cultura/Ciudad Juárez, Chihuahua". Recuperado de https://rancholasvoces.blogspot.com/search?q=mar\%C3\%ADa+luisa+puga [21/01/2006).

PARRINI ROSES, Rodrigo (2008): Los contornos del alma, los límites del cuerpo: género, corporalidad y subjetivación. México, Universidad Nacional Autónoma de México. Programa de Estudios de Género.

SANGUINO, Julieta (2015): "El arte fractal y las matemáticas". Cultura Colectiva, 05 de julio, 2015. Recuperado de https://culturacolectiva.com/arte/el-arte-fractal-y-lasmatematicas [1-5] [22/11/2018].

SONTAG, Susan (1996): La enfermedad y sus metáforas. Madrid, Taurus. 
ZAVALA, Lauro (2004): "Fragmentos, fractales y fronteras: género y lectura en las series de narrativa breve”. Revista de Literatura (ILLA, CSIC), vol. 66, núm. 131 (2004): 5-22. DOI: https://doi.org/10.3989/revliteratura.2004.v66.i131.138

(C) Elsa Leticia García Argüelles

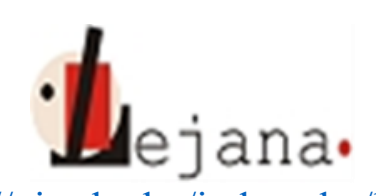

http://ojs.elte.hu/index.php/lejana

Universidad Eötvös Loránd, Departamento de Español, 1088 Budapest, Múzeum krt. 4/C 